\title{
COVID-19 and Quarantine: Indicators of Domestic Violence in Kosovo
}

\section{Besim Gollopeni ${ }^{1}$, Ferdi Kamberi ${ }^{2}$}

1 University of Mitrovica "Isa Boletini"

Street Ukshin Kovacica, 40000 Mitrovica, Republic of Kosovo

2 University of Prishtina

Rr. "George Bush", p. n., 10000 Prishtinë, Republika e Kosovës

DOI: $10.22178 /$ pos. $64-5$

LCC Subject Category:

HN50-995

Received 16.09.2020

Accepted 28.10.2020

Published online 30.11 .2020

Corresponding Author:

Ferdi Kamberi

ferdikamberi04@gmail.com

(c) 2020 The Authors. This article

is licensed under a Creative Commons

Attribution 4.0 License @) (1)
Abstract. Like many other countries in the world, Kosovo has faced a severe public health situation as a result of COVID-19. Kosovar society has been quarantined to protect it from the spread of COVID-19. Putting the community into quarantine has had a positive effect on stopping the spread of COVID-19; however, it has harmed domestic violence in Kosovar society, increasing the number of cases. This study aims to show the extent of violence and the causes of domestic violence in Kosovar society. The survey results show that domestic violence in Kosovo has increased (by $19.75 \%$ ) during the COVID-19 pandemic compared with the same months in the previous year (2019). The leading causes of domestic violence are stress (18.9\%), socio-economic insecurity $(11.4 \%)$, and a lack of physical space in the house/apartment $(4.4 \%)$.

Keywords: COVID-19; quarantine; violence; family; causes; Kosovo.

\section{INTRODUCTION}

The global society during 2020 has faced the unusual phenomenon of COVID-19. The spread of COVID-19 in Wuhan, China, in late 2019 seemed a priori to be the localized disease. Still, it spread rapidly in early 2020 to many parts of the world, alerting contemporary society that it faces an invisible, unknown enemy that will produce unforeseen consequences. Epidemics and pandemics have accompanied humanity throughout the developmental stages to the present day.

According to the World Health Organization (WHO), a pandemic is spreading a new disease across the world. A pandemic occurs when an epidemic spread between countries; in the case of COVID-19 specifically, the WHO claimed that it is the first pandemic caused by a coronavirus [1]. Also, "a pandemic is the highest possible level of disease or a measure of how many people have contracted a particular disease and how widespread it is. However, before a common disease can reach pandemic proportions, it must overcome several other levels, which according to the
Centers for Disease Control and Prevention (CDC) are: sporadic, endemic, epidemic and pandemic" [1].

Pandemics have appeared and taken the lives of millions of people, changed the histories and geographies of many early civilizations, and occurred from time to time to the present day. Despite warnings from health experts about the possible spread of COVID-19, few countries believed that such a SARS could reach developed countries like those in Europe. On the one hand, this left many European countries unprepared to deal with such a pandemic; on the other hand, society and institutions ignoring this SARS resulted in many cases of infection and fatalities.

In Kosovo, the first cases of COVID-19 were identified in March 2020. Immediately after the identification of COVID-19 issues, Kosovo institutions put in place measures to prevent it from spreading, leading to the halting of teaching in school institutions and working (apart from essential staff) in the public and private sector, the closure of the hospitality industry, the stopping of other 
cultural, sports, and political activities and quarantine. During this period, the spread of COVID-19 cases was under institutional control and management; however, other social problems emerged in families and Kosovar society at this stage. The emergence of domestic violence was one of the social issues that the Kosovar organization was facing, and it was continually growing.

Domestic violence is a universal phenomenon to which individuals of all ages and genders are exposed in all communities and cultures. The social infrastructure of violence is also robust to the point of violent behaviour being accepted within a society because the community's culture in which an individual life reveals expectations regarding how he or she will behave, think, or act [6]. According to the World Health Organization, violence as "the intentional use of physical force or power, threatened or actual, against oneself, another person, or against a group or community, which either results in or has a high likelihood of resulting in injury, death, psychological harm, maldevelopment, or deprivation [9]". In 1993, the United Nations General Assembly designated violence against women as an act of gender-based violence that results in or is likely to cause physical, sexual, or mental harm or suffering to women, including threats of such acts, coercion, or arbitrary deprivation of liberty, whether occurring in public or private life [8]. Studies have shown that violence against women and children increases with alcohol and drug use, mental health issues, and inadequate housing [5, 3].

Within months, the local epidemic became a global pandemic that forced governments worldwide to demand social distancing and, ultimately, quarantine [4]. Quarantining the society has increased the number of cases of domestic violence. In quarantine, life has become more difficult for many Kosovar families because they face socialeconomic insecurity, stress, anxiety, and violent family members, who make their lives as dangerous as the pandemic itself.

This study aims to analyze, compare, and reflect on the dynamics of the increase in domestic violence in general and the causes of domestic violence in Kosovar society in a time of quarantine (COVID-19). The study does not focus on a particular type of domestic violence because this is not the task's interest; it concentrates more on the presence of domestic violence during quarantine and the issues that lead to domestic violence in Kosovo.

\section{Statistics of domestic violence in Kosovo}

Recent studies have shown an increase in the number of domestic violence cases in many parts of the world. India, Canada, and the UK have witnessed a surge in violence against women, especially domestic violence, in the context of the COVID-19 pandemic lockdown [2]. According to the most recent update, in India, in the first four phases of lockdown (between March 25 and May $31,2020), 1,477$ complaints of domestic violence were made by women. This 68-day period recorded more complaints than those received between March and May in the previous ten years. However, reports have indicated that this alarming rise is just the tip of the iceberg as $86 \%$ of women who experience domestic violence do not usually seek help in India [2]. There is a similar situation in Canada. The federal government stated that there had been a 20 to $30 \%$ increase in gender-based violence. The police in Toronto reported that domestic incidents have increased by between 18 and $22 \%$. The Native Women's Association of Canada conducted a nationwide, grassroots consultation and found that one in five indigenous women had been a victim of violence over the previous three months of the pandemic. Indigenous women reported being more concerned about domestic violence risks than those of COVID-19 [2].

In the UK, in the first four weeks of the lockdown, the number of domestic killings doubled - 13 women and four children. London's Metropolitan Force reported that calls about domestic abuse had risen by about a third. Its officers were making around 100 arrests a day for such offences in the six weeks of the lockdown leading up to April 19; more than 4,000 arrests were made across London. West Yorkshire Police reported that, during the lockdown period between March 17 and April 19, it had responded to 6,704 domestic abuse calls - a rise of $1.2 \%$ compared with the previous month [2].

At the time when Kosovo entered quarantine, the number of cases of domestic violence increased. From March to June 2020, 691 cases of domestic violence were registered with the Kosovo Police. Compared with the same period in the previous year (2019), the number of domestic violence cases increased by $19.75 \%$. Domestic violence has affected all age groups, but, unlike last year, there has been an increase in the number of violence cases among children and young people ( 0 18 years old) and age groups over 71 years old. 
The fact that domestic violence has increased among children and the elderly remains a matter of concern. Cases of violence against children have increased by about $276.9 \%$, and these statistics show an alarming situation in Kosovar society. See the chart below.

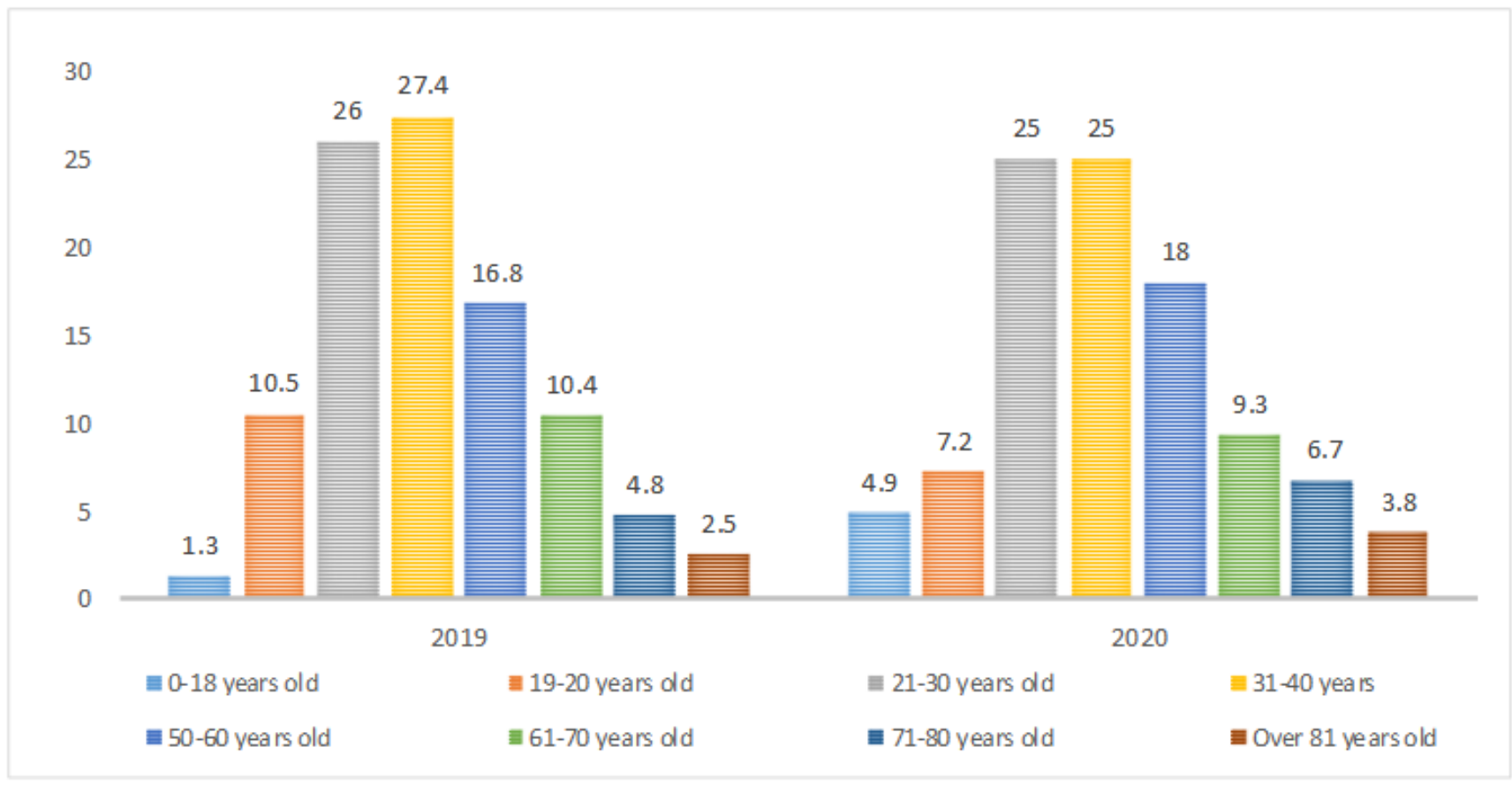

Figure 1 - Cases of domestic violence in Kosovo by age group (in percentages), from March to June 2019 and 2020

Source: Kosovo Police (data were received in an email dated August 20, 2020)

The statistics show that domestic violence has mainly affected women. In 2019 (March to June), $80.5 \%$ of violence cases were registered with the Kosovo Police by women, while, in the same period in 2020, $73.6 \%$ were recorded by women, showing a slight decrease (6.9\%). The statistics indicate that, during the quarantine period, there was an increase in the number of cases of domestic violence among men (from $19.5 \%$ in 2019 to $26.4 \%$ in 2020 or an increase of about $7 \%$ ).

Of the total number of domestic violence cases in Kosovo, during the pandemic (March to June 2020), $42 \%$ of violence cases occurred between spouses, and $28.1 \%$ of patients were between parents and children; other issues involved brothers and sisters and other family members. Cases of domestic violence have affected all structures of society and have occurred throughout the country. The Pristina region leads with the largest number of cases, followed by Ferizaj and other areas.

\section{METHODS}

A total of 908 respondents participated in the study, which was conducted from July 27 to $\mathrm{Au}$ gust 23, 2020. The survey participants are resident citizens of Kosovo and adults (over 15 years old); $68 \%$ are women, and $32 \%$ are men. Regarding the respondents' age included in the study, it varies from 15 to 79 years old. The age group of $15-20$ years is represented by $7 \%$ of participants, that of 21-30 years is represented by $34 \%$, that of $31-40$ years is represented by $36 \%$, that of $41-50$ years is represented by $16 \%$, that of $51-60$ years is represented by $5 \%$, and the age group over 61 is represented by $2 \%$. The mean age of the respondents (male and female) is 39 years ( $\mathrm{SD}=8.9$ ).

The respondents' level of qualifications is the following: primary education: $1.1 \%$; secondary education: $18.2 \%$; and higher education (necessary studies, master's, and Ph.D.): $80.7 \%$. The average is 15.1 ( $\mathrm{SD}=3.3$ ). Of the survey participants, $30 \%$ are from rural areas, and $70 \%$ are from urban areas. Furthermore, $60 \%$ live in a house, while 40 $\%$ live in an apartment. Of the total number of 
respondents included in the study, $12 \%$ have been infected with COVID-19. Before starting to complete the questionnaire, the respondents received information and instructions for completing the instrument.

Table 1 - Descriptive analysis of study respondents

\begin{tabular}{|l|l|}
\hline $\begin{array}{c}\text { Number of } \\
\text { respondents, } \\
\text { total - 908 }\end{array}$ & \multicolumn{1}{|c|}{$\%$} \\
\hline Gender & Male 32 \\
& Female 68 \\
\hline Age group & $15-20,7$ \\
& $21-30,34$ \\
& $31-40,36$ \\
& $41-50,16$ \\
& $51-60,5$ \\
& Over 61, 2 \\
\hline Education level & Primary school 1.1 \\
& Secondary school 18.2 \\
& University studies (Bch., \\
& MSc. Ph.D.) 13 \\
\hline Rural-Urban & Rural 30 \\
& Urban 70 \\
\hline Residential & Home 60 \\
& Flat 40 \\
\hline
\end{tabular}

The study was comprehensive and was conducted with a representative sample. Based on the sample number $(\mathrm{N}=908)$ and the inclusion, we can reach conclusions.

The authors designed the instrument and implemented online (Google Form), distributed via the Internet and social media. The participants were asked to rate each question on a Likert scale - (4) a lot, (3) average, (2) little, and (1) not at all - and in some cases to select one of the given solutions. At the end of the instrument, open space was left where the respondents could express their free opinion. This part helped us considerably in understanding the respondents' thoughts and experiences. According to Cronbach's alpha score, we have good questionnaire reliability, with 820 . The statistical package used in this study was SPSS Version 20.0.

\section{RESULTS AND DISCUSSIONS}

Many social topics related to epidemics and global pandemics have been discussed, and one of those topics has undoubtedly been domestic violence. Domestic violence has had an important place since it has been influenced by the pandemic's new situation (COVID-19). Citizens were not prepared for the changes in the way of life resulting from the pandemic and had difficulty accepting these social changes, leading to increased domestic violence cases.

Of course, this situation has brought many unknowns to society. To understand more about society's awareness of global epidemics and pandemics and their discipline in facing the constraints that prevent the spread of COVID-19, the study starts with a specific question: do you know about global epidemics and pandemics? In those countries where there was a lack of awareness and discipline of citizens and in those societies that did not act in time to prevent the spread of COVID-19 or ignored this need, COVID-19 spread rapidly, and consequently; there were many cases of infection and fatalities (Italy, etc.). The study's findings show that $24 \%$ of citizens in Kosovo have basic knowledge about global epidemics and pandemics, $64.1 \%$ of citizens have the average ability, and about $12 \%$ of citizens have little or no understanding of global epidemics and pandemics.

The study results show a high average level of knowledge about global epidemics and pandemics among citizens; however, this highlights the fact that most of the survey participants are highly educated, and it is natural to some extent for the results to be above average. The results show that $12 \%$ of citizens have little or no knowledge of global epidemics and pandemics. Between those who have no understanding of global epidemics and pandemics and those who do not believe in the existence of COVID-19, there is a significant positive correlation: $r=.267^{* *}, \mathrm{p}<0.01$. Of the total number of study participants ( $\mathrm{N}=908), 11.9 \%$ do not believe in or do not have an attitude toward the existence of COVID-19. Citizens' doubt about COVID-19 makes it more difficult for public institutions to work since this category of society follows the guidelines of institutions aimed at preventing the spread of COVID-19 only partially or not at all and thus has a direct impact on the space of COVID-19 to society.

About two-thirds of citizens before the COVID-19 pandemic did not believe that a pandemic (COVID-19) could occur in Kosovo. Citizens associated the disbelief that COVID-19 could not arise in Kosovo because it is part of Europe. This is the 21st century, when science, medicine, and technology have evolved so much that they can prevent global pandemics like COVID-19. According 
to them, pandemics like COVID-19 can occur in the poorest countries but not on the European continent. The appearance of the first cases in Europe (Italy) and later in Kosovo (March 2020) led Kosovar institutions to take preventive measures to maintain public health by imposing restrictions on travelling to and from work, closing schools, maintaining personal hygiene and physical and social distance, and putting the country into quarantine. Quarantining, the government changed the course of ordinary life, and society is facing many unknowns in the social, economic, and political fields and the central area of public health. Circumstances like these have caused fear, social anxiety, and stress among citizens. The study results show that the quarantine (blocking) has been very stressful for Kosovar society.

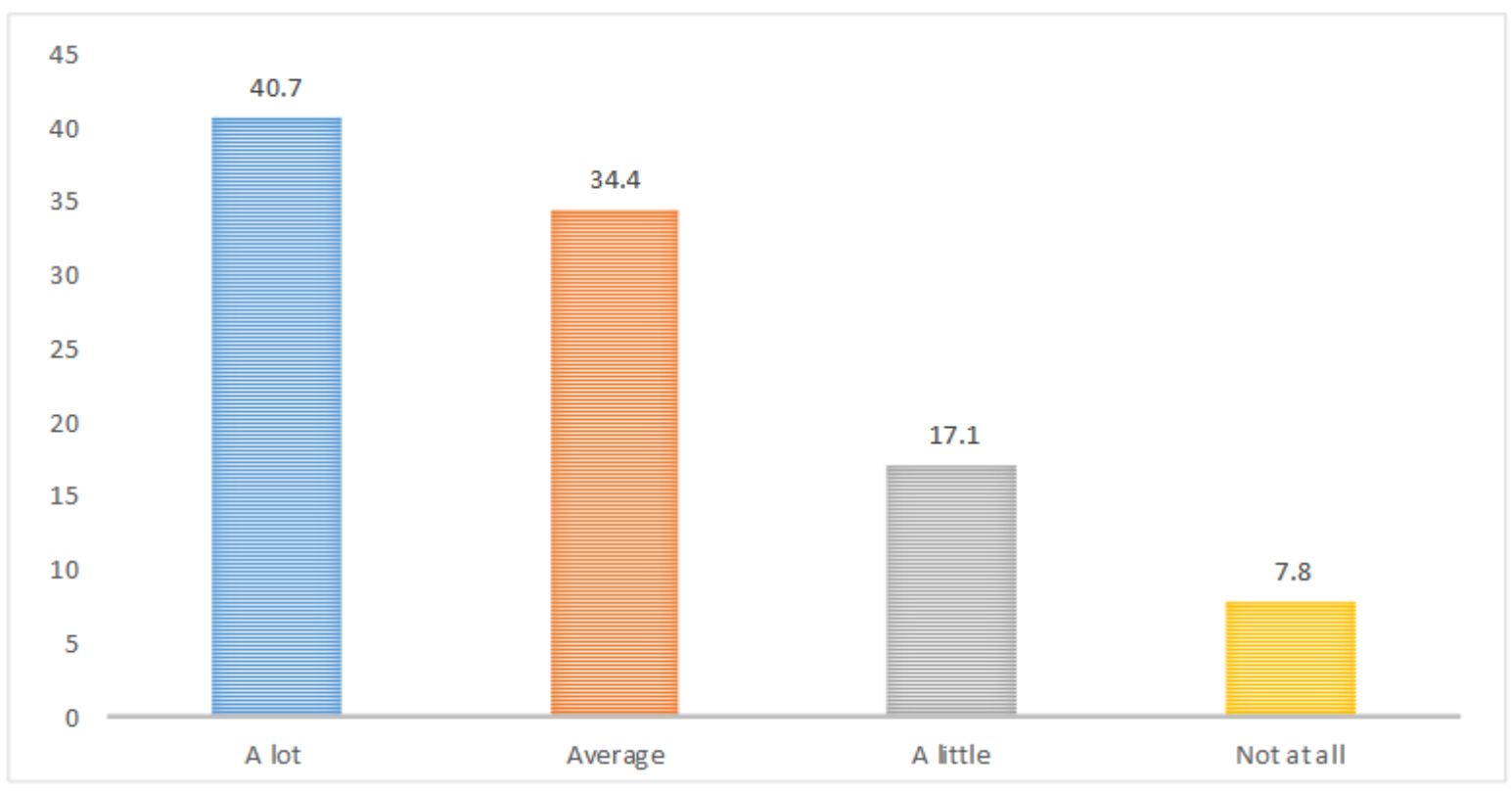

Figure 2 - Has social isolation (quarantine) been stressful for you?

The study results show that, for $41 \%$ of citizens, the period of social isolation (quarantine) was very stressful. For $34 \%$, it was moderate, and for about $25 \%$ of citizens, it was a little or not at all stressful. Stressful situations cause fear, panic, social anxiety, and depression and affect domestic violence manifestation. However, to the extent that domestic violence was present during the pandemic in Kosovar society, the study results show that $42 \%$ of the study participants during the quarantine period experienced domestic violence (conflicts) in the family.

For $4.1 \%$ of the study participants, domestic violence (conflicts) was very present. In contrast, for $8.9 \%$ of the study participants, there were average family conflicts, $29.1 \%$ had few cases of domestic violence (clashes), and for $58 \%$ of the participants, the results of the study show that there was no domestic violence (conflicts) in the family during the quarantine period. Thus, the results show that more than $40 \%$ of the study participants experienced domestic violence (matches) in
Kosovo during the quarantine. Based on the study's findings and the statistics of the Kosovo Police on domestic violence in Kosovo, we find that domestic violence is present at a high rate and, compared with last year's statistics for the same period, it has increased (19.75\%).

The causes of domestic violence are different and vary in time and space. They also change as a result of the new social circles in society. The study results show that stress is among the leading causes of domestic violence in Kosovo (18.9\%).

Stress is one of the main issues that led to domestic violence in Kosovar society during the quarantine. Many citizens, facing high unemployment rates, poverty, and economic instability on the one hand and COVID-19 on the other, have experienced stress. Stress (18.9\%), financial insecurity ( $8.5 \%$ ), a lack of physical space (4.4\%), the division of duties and responsibilities among family members (4.4\%), and other problems are the main issues that have led to domestic violence in Kosovo. 


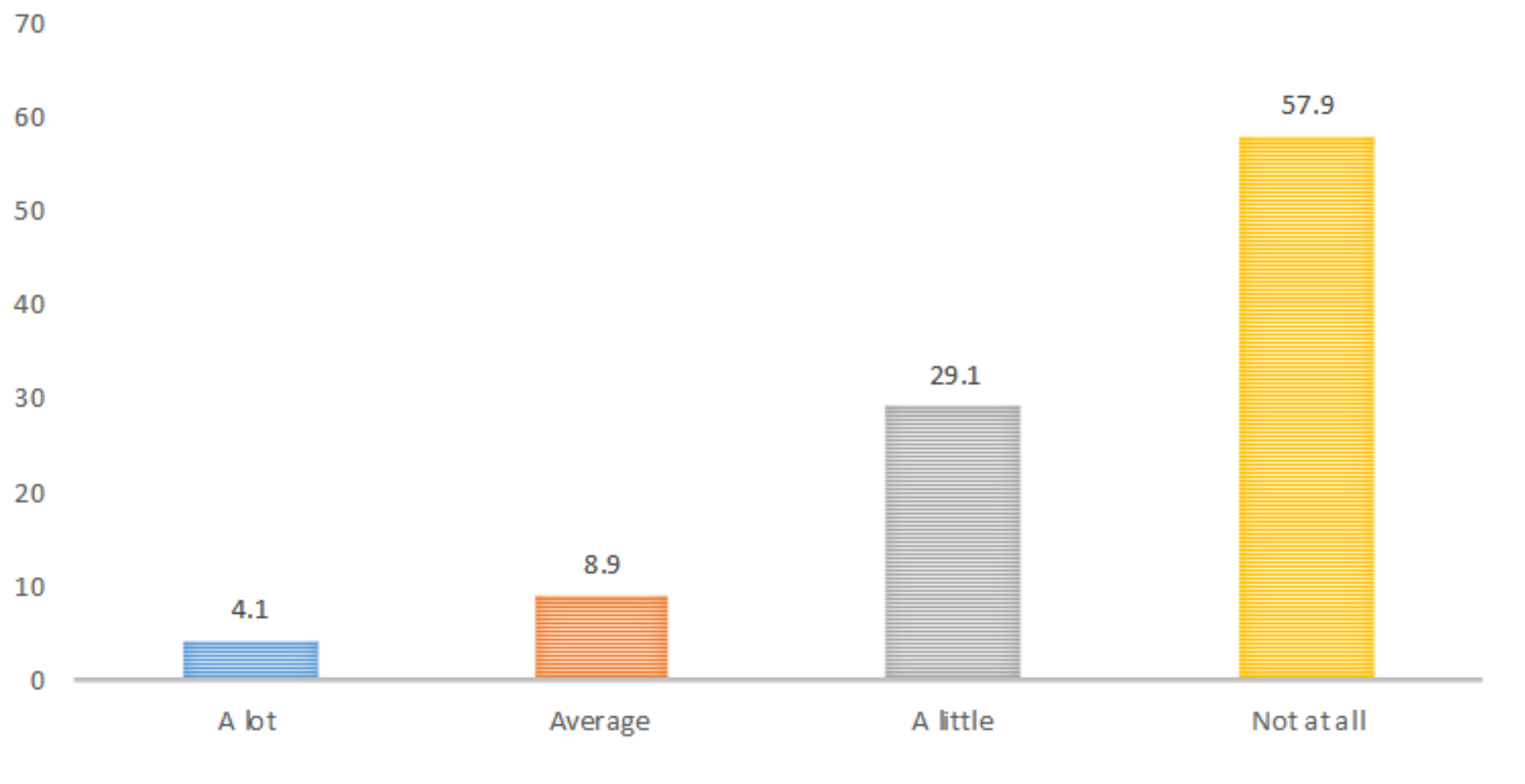

Figure 3 - Were there any cases of domestic violence in your family during quarantine (Covid-19)?

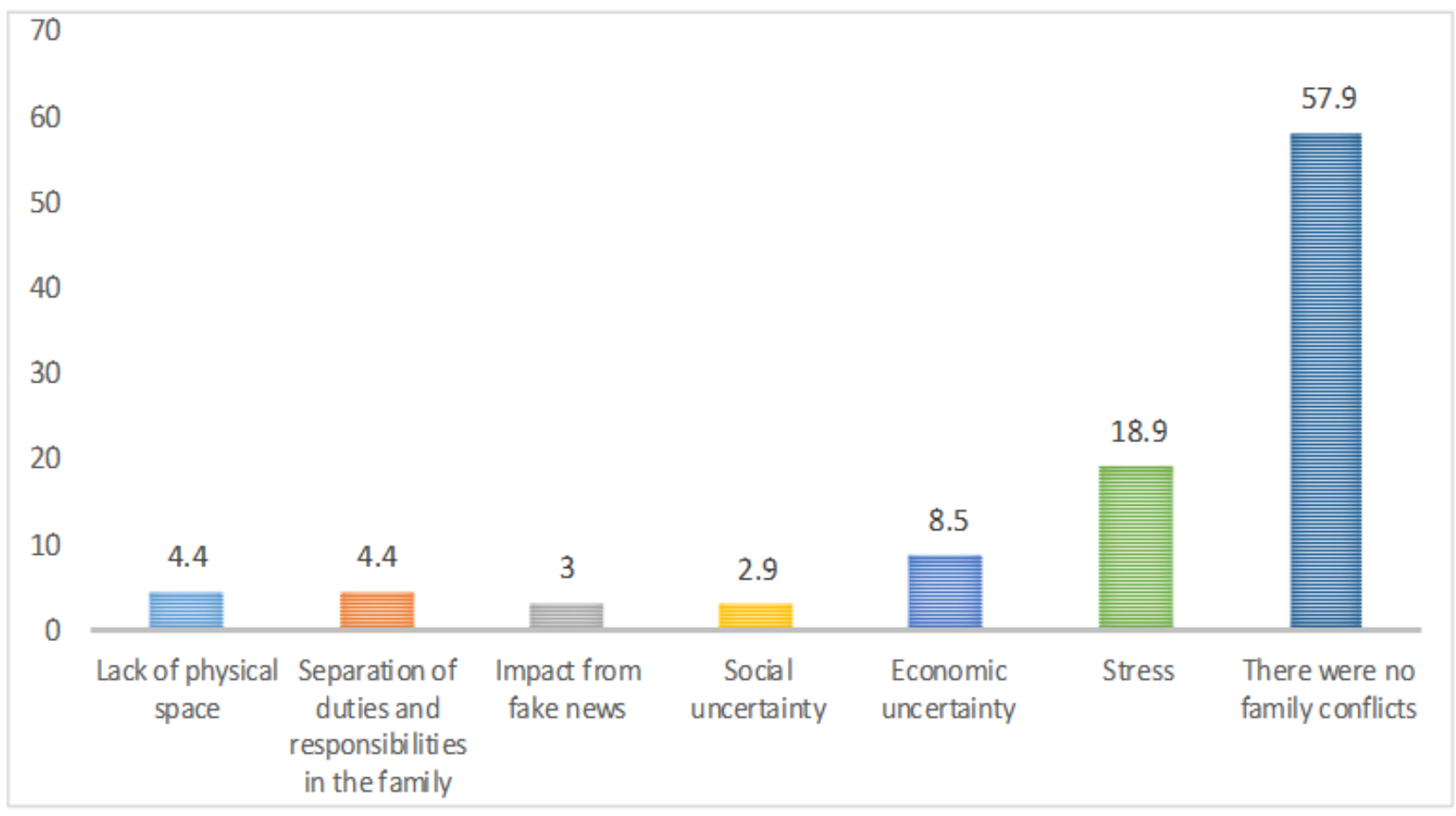

Figure 4 - What were the leading causes that led to domestic violence (conflicts)?

Quarantine has introduced many unknowns into the Kosovar society, leading to stress, socio-economic insecurity, and a lack of separation of duties and responsibilities in the family. All these have led to domestic violence.

\section{CONCLUSIONS}

Domestic violence is not new; it has accompanied society through all the stages of its development. In many conservative institutions and the Kosovar community, topics such as domestic violence have been taboo. However, with the increase in the level of education and social emancipation in 
general and the liberation of women in particular, domestic violence is being discussed more and more, and cases of domestic violence are increasingly being denounced in the relevant institutions.

Domestic violence in Kosovo increased (by $19.75 \%$ ) during quarantine (COVID-19) compared with the same months (March to June) of last year (2019). Domestic violence has affected all social structures; however, it has mainly affected people aged 20 and 40 and women. Domestic violence against women during the quarantine period marked a slight decrease compared with the same months last year. Otherwise, the number of domestic violence cases during the time of quarantine has increased among men (male victims). Based on the study results, every third interviewee in Kosovo experienced domestic violence during quarantine (COVID-19).

The causes of domestic violence in Kosovar society are many and varied. Increased stress, socioeconomic insecurity, the division of duties and responsibilities among family members, and the lack of physical space (housing) are the main issues that have led to domestic violence in Kosovo.

\section{REFERENCES}

1. Brabaw, K. (2020, March 13). Epidemic Vs. Pandemic: What exactly is the difference? Retrieved from https://www.health.com/condition/infectious-diseases/epidemic-vs-pandemic

2. Campbell, M. (2020, July). Domestic violence and COVID. Retrieved from https://www.researchgate.net/publication/342601329_Domestic_Violence_and_COVID

3. Freisthler, B., Wolf, J. P., Wiegmann, W., \& Kepple, N. J. (2017). Drug Use, the Drug Environment, and Child Physical Abuse and Neglect. Child Maltreatment, 22(3), 245-255. doi: 10.1177/1077559517711042

4. Holshue, M. L., DeBolt, C., Lindquist, S., Lofy, K. H., Wiesman, J., Bruce, H., ... Pillai, S. K. (2020). First Case of 2019 Novel Coronavirus in the United States. New England Journal of Medicine, 382(10), 929-936. doi: 10.1056/nejmoa2001191

5. Oudesluys-Murphy, A. M., Diderich, H. M., Dechesne, M., \& Buitendijk, S. E. (2015). Violence against women: do not forget their children! The Lancet, 385(9977), 1505. doi: 10.1016/s01406736(15)60744-9

6. Terzioğlu, F. \& Taşkın, L. (2008). Kadının Toplumsal Cinsiyet Rolünün Liderlik Davranışlarına Ve Hemşirelik Mesleğine Yansımaları. C.Ü. Hemşirelik Yüksekokulu Dergisi, 12(2), 62-67.

7. Tuna Uysal, M., \& Tan Eren, G. (2020). A study on men's violence and domestic violence descriptions. Journal of History Culture and Art Research, 9(1), 423. doi: 10.7596/taksad.v9i1.2446

8. United Nations Human Rights. (1993). Declaration on the elimination of violence against women. Retrieved from https://www.ohchr.org/en/professionalinterest/pages/violenceagainstwomen.aspx

9. World Health Organization. (2002). World report on violence and health. Retrieved from https://www.who.int/violence_injury_prevention/violence/world_report/en/full_en.pdf?ua=1 